\title{
URETEROPELVIC JUNCTION OBSTRUCTION IN CHILDREN: TWO VARIANTS OF THE SAME CONGENITAL ANOMALY?
}

\author{
LUIS H.P. BRAGA, AGNES LIARD, BRUNO BACHY, PAUL MITROFANOFF \\ Department of Pediatric Urology, Charles Nicolle University Hospital, Rouen, France
}

\begin{abstract}
Objective: To compare the characteristics of prenatally and postnatally diagnosed ureteropelvic junction obstruction (UPJO) in children.

Patients and Methods: We reviewed the records of 74 children who underwent pyeloplasty or nephrectomy for UPJO between 1995 and 2000. The patients were divided into 2 groups: prenatally and postnatally diagnosed UPJO. In each group, we compared age at surgery, gender, affected side, anteroposterior diameter (APD) of the renal pelvis, surgical findings, and renal function as determined by creatinine clearance.

Results: Of the 74 children, $44(59.4 \%)$ had a prenatal diagnosis of UPJO and 30 (40.6\%) had a postnatal diagnosis despite the fact that all had had a fetal ultrasonography. Median age at the time of surgery was 6.3 years ( 4 months to 16 years) for children with postnatal UPJO and 3.6 months (1 month to 4 years) for the prenatal group. Forty-three percent of the children in the postnatal group and $25 \%$ in the prenatal group were females. Clinical manifestations in children with postnatal UPJO included abdominal pain in $13(43 \%)$ patients, pyelonephritis in 7 (23\%), urinary tract infection in 5 $(16.6 \%)$, and occasional findings upon ultrasound in 5 (16.6\%). Excretory urography suggested obstruction in most children. The surgical findings included ureteral kinks due to adhesions in $93.3 \%$ of postnatally diagnosed UPJO cases and in $27.3 \%$ of prenatal cases $(\mathrm{p}<0.01)$. A reduction in mean creatinine clearance of hydronephrotic kidneys was observed for both groups when compared to reference values for the respective ages, but this difference was not statistically significant.

Conclusions: Postnatally diagnosed UPJO may be considered, at least in part, an entity different from prenatally detected obstruction due to its peculiar characteristics, i.e., postnatal UPJO more frequently affects females, manifests later in life with urinary infection or abdominal pain, and is frequently associated with ureteral kinking.
\end{abstract}

Key words: kidney pelvis; ureter; hydronephrosis; pyeloplasty; ultrasonography, prenatal; postnatal

Int Braz J Urol. 2003; 29: 528-534

\section{INTRODUCTION}

Hydronephrosis caused by ureteropelvic junction obstruction (UPJO) is one of the most frequent anomalies affecting the fetus, being responsible for $34 \%$ of urinary disorders observed during the intrauterine period (1).

Prenatal ultrasonography has been the method of choice for the diagnosis and follow-up of these malformations. The later the ultrasound examination is performed, the higher its sensitivity in detecting dilatations of the urinary system, thus leading to the diagnosis of most UPJO cases still during the prenatal period (2-4). The routine use of fetal ultrasonography has led to a change in the form of presentation of children with hydronephrosis who could be diagnosed early and without symptoms $(5,6)$. This has contributed to a better understanding of the 
natural history of the disease, but some aspects remain to be clarified. For example, an apparently late onset of UPJO was observed in schoolchildren, despite the fact that these patients showed a normal prenatal ultrasound.

Therefore, the objective of the present study was to compare groups of children with postnatally and prenatally diagnosed UPJO in an attempt to determine the differences between them and to better understand the natural history of the disease.

\section{PATIENTS AND METHODS}

\section{Study Design}

We retrospectively reviewed the records of 74 children submitted to pyeloplasty or nephrectomy due to UPJO between 1995 and 2000.

\section{Inclusion Criteria}

Only patients with unilateral UPJO were included in the study. The patients were divided into 2 groups: $44(59.4 \%)$ children with a prenatal diagnosis of UPJO and $30(40.6 \%)$ children with a postnatal diagnosis of UPJO. Records of maternal pregnancy were reviewed to determine whether fetal ultrasonography had been performed and, if so, what the timing and findings of the examination were. All children had a prenatal ultrasonography at the first, second and third trimester of gestation as it is the rule in our country.

Prenatal UPJO was defined when the diagnosis was made during gestation, considering as hydronephrosis an anteroposterior diameter (APD) of the renal pelvis greater than $9 \mathrm{~mm}$. Postnatal UPJO was defined by the absence of upper urinary tract dilatation or by an APD of the renal pelvis equal to or lower than $9 \mathrm{~mm}$ as determined by ultrasonography during the third trimester of gestation.

\section{Exclusion Criteria}

Children with contralateral renal or bladder anomalies were excluded. None of the patients needed to be excluded from the study due to the lack of ultrasound during pregnancy. Fifty $(67.5 \%)$ children even had two exams during the third trimester.

\section{Surgical Aspects - Indication}

The indication for pyeloplasty in $80 \%$ of the children of the prenatal group was based on the obstructive pattern observed upon excretory urography. Obstruction was defined as a pronounced dilatation of the pelvis and renal calices accompanied by a greatly prolonged drainage time $(>3 \mathrm{~h})$, based on the classification of Bachy et al. (7). Mercaptoacetyltriglycine (MAG-3) scintigraphy was used when excretory urography showed slow renal excretion but not the obstructive pattern described above. A plateau curve determined by MAG-3 scintigraphy was considered indicative of obstruction.

In the postnatal group, symptoms were indicative of pyeloplasty in $25(83 \%)$ patients. In the remaining $5(16.6 \%)$ cases, surgical intervention was indicated based on the obstructive pattern observed upon excretory urography.

\section{Surgical Technique}

In all children, we performed AndersonHeynes pyeloplasty by posterior lumbotomy (8). A drain was placed in the perinephric space and a nephrostomy catheter was left in place for 5 days.

\section{Comparative Analysis of Clinical and Surgical Aspects}

We compared age at surgery, gender, affected side, APD of the renal pelvis, surgical findings, and renal function between the 2 groups. The pelvic diameter was determined by ultrasonography before surgery. The surgical findings were obtained from the surgical records and were classified as intrinsic stenosis when a tiny passage was observed at the ureteropelvic junction, and as ureteral kinking when the proximal ureter was folded and attached to the renal pelvis by adhesions, reducing urine drainage. The presence or absence of crossing vessels was recorded.

Renal function was measured by creatinine clearance of both kidneys on the 2nd postoperative day. Twenty-four hour urine was collected from the hydronephrotic kidney using the nephrostomy catheter and from the normal kidney using a Foley catheter. Creatinine clearance of the hydronephrotic kidney obtained for each patient was evaluated according to a reference value for age. 


\section{Statistical Analysis}

Statistical analysis was performed with the EPI-INFO program, version $6.04 \mathrm{~b}$, using the chi-square test, with the level of significance set at $\mathrm{p}>0.05$.

\section{RESULTS}

\section{General Clinical Characteristics}

A total of 74 children were included in the study, 30 (40.6\%) with postnatally diagnosed UPJO and $44(59.4 \%)$ with prenatally diagnosed UPJO.

Two patients in the postnatal group were submitted to nephrectomy due to renal failure. Dimercaptosuccinic acid scintigraphy revealed less than $10 \%$ renal function in these children compared to the contralateral kidney. Their records showed no dilatation in fetal ultrasonography.

Median age at the time of surgery was 3.6 months (1 month to 4 years) for the prenatal group and 6.3 years ( 4 months to 16 years) for the postnatal group. A difference in gender was observed between groups, with $11(25 \%)$ children of the prenatal group and $13(43.3 \%)$ of the postnatal group being females, but this difference was not statistically significant $(\mathrm{p}=0.09)$. The left kidney was affected in $32(72.7 \%)$ children with prenatal UPJO and in $20(66.7 \%)$ children with postnatal UPJO (Table-1). Clinical manifestations in children with postnatal UPJO included abdominal pain in 13, pyelonephritis in 7 , urinary tract infection in 5, and abnormal findings at occasional ultrasonography in 5.

Table 1 - General clinical characteristics of the patients.

\begin{tabular}{lcc}
\hline Variable & $\begin{array}{c}\text { Prenatal Group } \\
\mathbf{n = 4 4}\end{array}$ & $\begin{array}{c}\text { Postnatal Group } \\
\mathbf{n = 3 0}\end{array}$ \\
\hline Gender Female & $11(25 \%)$ & $13(43.3 \%)$ \\
Male & $33(75 \%)$ & $17(56.7 \%)$ \\
Age Minimum & 1 month & 4 months \\
Median & 3.6 months & 6.3 years \\
Maximum & 4 years & 16 years \\
Affected Side & & \\
Right & $32(72.7 \%)$ & $20(66.7 \%)$ \\
Left & $12(27.3 \%)$ & $10(33.3 \%)$ \\
\hline
\end{tabular}

\section{Clinical and Surgical Findings}

The mean diameter of the renal pelvis was found to be increased in the postnatal group (45.8 $\mathrm{mm}$ vs. $31.8 \mathrm{~mm}$ in the prenatal group). The APD of the renal pelvis was greater than $20 \mathrm{~mm}$ in $27(61.4 \%)$ patients with prenatal UPJO and in all patients with postnatal UPJO. No crossing vessels were observed in either group.

Ureteral kinking due to adhesions between the ureter and renal pelvis was observed in 28 children with postnatal UPJO. Only $2(6.7 \%)$ patients with postnatal UPJO showed intrinsic stenosis at the ureteropelvic junction. On the other hand, intrinsic stenosis was observed in $32(72.7 \%)$ and kinking in $12(27.3 \%)$ children of the prenatal group, with this difference being statistically significant $(\mathrm{p}<0.01)$ (Figure-1).

\section{Renal Function}

Mean creatinine clearance of hydronephrotic kidneys was lower than normal values expected for age in both the postnatal and prenatal groups. Mean creatinine clearance of hydronephrotic kidneys in the prenatal group, with a median age of 3.6 months, was $33.3 \mathrm{ml} / \mathrm{min} / 1.73 \mathrm{~m}^{2}$. The reference value of unilateral creatinine clearance for children aged 3 to 4 months ranges from 23 to $60 \mathrm{ml} / \mathrm{min} / 1.73 \mathrm{~m}^{2}$ $($ mean $=41.5)$. Hydronephrotic kidneys in the prenatal group showed a $19.8 \%$ decrease compared to normal unilateral creatinine clearance values (33.3 x 41.5). For the postnatal UPJO group with a median age of 6.3 years, the corresponding normal unilateral creatinine clearance is 40 to $85 \mathrm{ml} / \mathrm{min} /$ $1.73 \mathrm{~m}^{2}$ (mean $\left.=62.5\right)$. The mean creatinine clearance value of $37.9 \mathrm{ml} / \mathrm{min} / 1.73 \mathrm{~m}^{2}$ observed in hydronephrotic kidneys of the postnatal group was therefore lower, representing a $39.4 \%$ reduction $(37.9 \times 62.5)$.

However, no statistically significant difference between the 2 groups was observed when comparing the percent decrease in mean creatinine clearance of hydronephrotic kidneys in relation to the respective mean unilateral normal values (19.8\% for the prenatal group compared to $39.4 \%$ for the postnatal group; $\mathrm{p}=0.07 / \div^{2}=3.35$ ) (Table-2). 


\section{Surgical Findings}

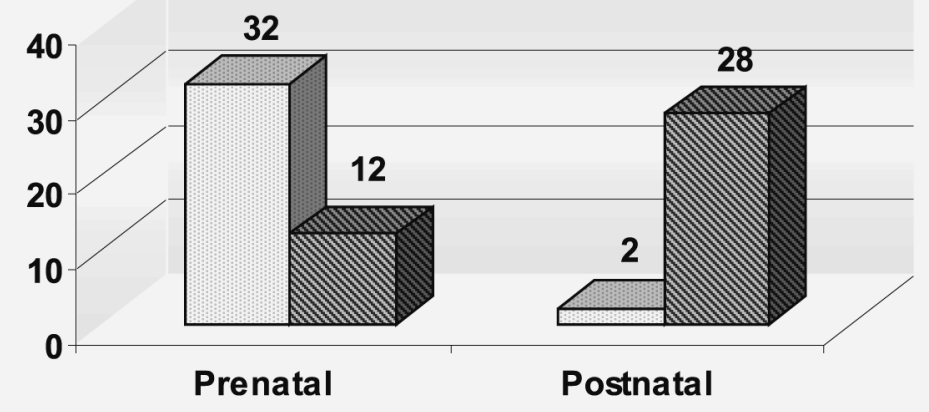

\section{$\square$ intrinsic stenosis $\mathbb{\text { kinking }}$}

Figure 1 - Comparison of frequencies of intrinsic stenosis and ureteral kinking in patients with prenatally and postnatally diagnosed ureteropelvic junction obstruction ( $p<0.01$ for both comparisons).

\section{DISCUSSION}

The introduction of prenatal ultrasonography has led to an earlier diagnosis of UPJO (2). Therefore, one would not expect to find children with large hydronephrotic and symptomatic kidneys. Clinical practice, however, has shown that we continue to treat patients with voluminous hydronephrosis diagnosed later in life even though these patients showed normal prenatal ultrasounds. The objective of the present study

Table 2 - Comparison of creatinine clearance in patients with prenatally and postnatally diagnosed ureteropelvic junction obstruction ( $p=0.07 / \stackrel{\div}{\div}^{2}=3.35$ for comparison between percent decrease in mean creatinine clearance of hydronephrotic kidneys and the age-matched unilateral reference value).

\section{Prenatal Group}

$$
\mathrm{n}=\mathbf{4 4}
$$

\section{6 months}

46 to $120 \mathrm{ml} / \mathrm{min} / 1.73 \mathrm{~m}^{2}$

$($ mean $=83)$

reference

value

Unilateral creatinine clearance age-

matched reference value

Mean creatinine clearance of

hydronephrotic kidneys

Percent decrease in mean creatinine clearance of hydronephrotic kidneys in relation to unilateral age-matched reference value

23 to $60 \mathrm{ml} / \mathrm{min} / 1.73 \mathrm{~m}^{2}$

$($ mean $=41.5)$
$33.3 \mathrm{ml} / \mathrm{min} / 1.73 \mathrm{~m}^{2}$

$19.8 \%$

(\% $\downarrow$ between

$41.5 \%$ and $33.3 \%$ )

\section{Postnatal Group}

$$
\mathbf{n}=\mathbf{3 0}
$$

\section{3 years}

79 to $170 \mathrm{ml} / \mathrm{min} / 1.73 \mathrm{~m}^{2}$ $($ mean $=124.5)$

40 to $85 \mathrm{ml} / \mathrm{min} / 1.73 \mathrm{~m}^{2}$

$($ mean $=62.5)$

$37.9 \mathrm{ml} / \mathrm{min} / 1.73 \mathrm{~m}^{2}$

$39.4 \%$

(\% $\downarrow$ between

$62.5 \%$ and $37.9 \%$ ) 
was precisely to identify these patients and to compare them with children with prenatally diagnosed UPJO.

The indication for pyeloplasty was based on excretory urography findings, as described by Bachy et al. (7). In contrast, in the literature, diethylenetriaminepentaacetic acid or MAG-3 scintigraphy is mainly used to determine the presence or absence of obstruction in hydronephrotic kidneys. Our choice of excretory urography as an approach to the identification of UPJO was based on 2 major aspects. The first concerned the need for identifying the anatomy of the kidney and ureter before pyeloplasty, permitting the execution of dorsal lumbotomy without the risk of finding renal rotation abnormalities or anatomical variations, which would have impaired surgery through this access route. Second, excretory urography is not influenced by as many factors as scintigraphy for which each team has a different examination protocol, thus impairing an adequate comparison between results. In this respect, Brookes \& Gordon (9) observed that the extent of patient hydration and the presence of a Foley catheter during scintigraphy interfered with the final result of the exams.

With respect to the diagnosis of hydronephrosis, it is unlikely that the postnatal group is due to false-negative examinations because, with modern equipment, even minor degrees of upper tract dilatation are readily demonstrable. The sensitivity of ultrasonography in detecting pelvic dilatation is known to increase with gestational age (3-6). In our series, all children underwent an ultrasound during the third trimester. It is part of our protocol to measure renal calyces when performing a routine fetal ultrasonography. All children in the postnatal group showed no calyectasis at the third trimester ultrasound.

We observed a sharp difference in patient age between the 2 groups. Median age at the time of pyeloplasty was 6.3 years for the postnatal group compared to 3.6 months for the prenatal group, suggesting that postnatally detected UPJO presented clinically later in life (10).

The left kidney was affected in $70 \%$ of cases in both groups, in agreement with the literature what shows a more frequent involvement of the left side in hydronephrosis (11).
Females were found to be more frequently affected in the postnatal group (43.3\%) than in the prenatal group (25\%). Although this difference did not reach statistical significance, a tendency toward a larger proportion of girls in the postnatal group was observed. One explanation for this observation might be due to urinary tract infections, which are known to occur more frequently in females and occurred in almost half of the children with postnatally diagnosed UPJO (12).

The APD of the renal pelvis before surgery was greater than $20 \mathrm{~mm}$ (mean $=23.8 \mathrm{~mm})$ in 27 (61.4\%) patients with prenatally diagnosed UPJO. This result is in accordance with the finding that kidneys with a pelvic diameter greater than $20 \mathrm{~mm}$ require pyeloplasty after a period of conservative treatment (13). A study by Dhillon (14) showed that in newborns with an APD greater than $20 \mathrm{~mm}$ the decision about surgery during follow-up continues to be difficult since spontaneous resolution was not observed in these cases.

No crossing vessels were observed in children with postnatal UPJO, in contrast to studies showing an incidence of up to $30 \%$ in this group (15). This finding may be due to the use of the posterior lumbotomy in all patients, which does not permit the identification of displaced or anteriorly hidden crossing vessels.

The most intriguing finding of the present study was the significant difference in the frequency of intrinsic stenosis and ureteral kinking between the 2 groups. The incidence of intrinsic stenosis in the postnatal group $(6.7 \%)$ was very low compared to the $72.7 \%$ rate observed for the prenatal group. Adhesions between the proximal ureter and the renal pelvis resulted in ureter kinking in 28 (93.3\%) children with postnatally detected UPJO, causing a reduction in urine drainage. It seems reasonable to consider the possibility that ureteral kinks may take some time to cause dilatation since they are the result of slowly developing adhesions and not of abnormal blood vessels. Therefore, hydronephrosis would only manifest after birth later in life. On the other hand, intrinsic stenosis could be the result of a congenital defect and, consequently, hydronephrosis would have already occurred and could be diagnosed during prenatal examination. 
In the present study, it was not possible to determine whether the involvement of ureteral kinking in the obstructive process increased with the progression of hydronephrosis. We only could demonstrate a higher frequency of kinking in older children (median $=6.3$ years) with UPJO $(93.3 \%)$ compared to the $27.3 \%$ rate observed for younger children $($ median $=3.6$ months $)(p<0.01)$.

The reduction in mean creatinine clearance of hydronephrotic kidneys in both groups compared to age-matched unilateral reference values suggests deterioration in renal function along time, as also observed by others $(10,13,16,17)$. It remains controversial, however, whether this loss of function of hydronephrotic kidneys is recoverable (18). In several studies, Koff et al. (19-21) pointed to the spontaneous improvement in reduced renal function and advocated nonsurgical treatment of hydronephrosis. MacNeily et al. (22) observed that increased patient age did not negatively influence the functional result of pyeloplasty. In a review on the natural history of hydronephrosis, Di Sandro \& Kogan (23) noted progressive renal deterioration on the affected side after conservative treatment in 15 to $30 \%$ of children. Ransley et al. (24), in their study on hydronephrosis, demonstrated that 7 of 23 kidneys with moderate renal function as determined by scintigraphy and submitted to pyeloplasty after a period of conservative treatment presented loss of function, which was not recovered after surgery.

It is therefore believed that some hydronephrotic kidneys may show loss of function along time. Nevertheless, 2 questions continue to intrigue pediatric urologists. Is there a real obstruction in the hydronephrotic kidney due to UPJO? Is the impaired renal function recoverable? Thus, the challenge remains to predict which hydronephrotic kidneys are at risk of renal damage, and to identify the time point at which this deterioration starts to appear. It seems therefore preferable to operate on patients with significant pelvic dilatation $(>20 \mathrm{~mm})$ and those who do not show improvement during follow-up than to leave them under observation because this last approach does not prevent the occurrence of permanent renal damage. Peters (25) and Hanna (26) suggested that UPJO should be considered responsible for renal deterioration until new diagnostic exams prove otherwise. Prospective, randomized studies are required to answer the question whether early pyeloplasty provides a greater benefit to the child.

Finally, the comparison of prenatally and postnatally diagnosed cases in the present study suggests the possibility of 2 clinical variants of UPJO, as also reported in the literature $(5,15)$. The first, prenatally detected form is more frequent in boys and shows intrinsic stenosis at the ureteropelvic junction in most cases. This obstruction is probably due to a congenital defect, causing the disease to manifest early and without symptoms. The second, postnatally detected form more frequently affects females, shows a symptomatic clinical picture with later manifestation and is frequently associated with ureteral kinking. In this second form, it remains possible that the defect causing UPJO is also congenital but that its expression, as hydronephrosis, may occur after birth.

Based on these peculiar characteristics, postnatally detected UPJO may be considered, at least in part, an entity different from prenatally diagnosed obstruction.

\section{REFERENCES}

1. Tam JC, Hodson EM, Choong KK, Cass DT, Cohen RC, Gruenewald SM, et al.: Postnatal diagnosis and outcome of urinary tract abnormalities detected by antenatal ultrasound. Med J Aust. 1994; 160: 633-7.

2. Wiener JS, Emmert GK, Mesrobian HG, Whitehurst AW, Smith LR, King LR: Are modern imaging techniques over diagnosing ureteropelvic junction obstruction? J Urol. 1995; 154: 659-61.

3. Barker AP, Cave MM, Thomas DF, Lilford RJ, Irving $\mathrm{HC}$, Arthur RJ, et al.: Fetal pelvi-ureteric junction obstruction: predictors of outcome. Br J Urol. 1995; 76: 649-52.

4. Nguyen HT, Kogan BA: Upper urinary tract obstruction: experimental and clinical aspects. Br J Urol. 1998; 81: 13-21.

5. Rickwood AMK, Harvey JV, Jones MO, Oak S: "Congenital" hydronephrosis: limitations of diagnosis by fetal ultrasonography. Br J Urol. 1995; 75: 52930. 
6. Brown T, Mandell J, Lebovitz RL: Neonatal hydronephrosis in the sonographic era. Am J Roentgenol. 1987; 148: 959-63.

7. Bachy B, Mitrofanoff P, Lechevallier J, Devos P, Bawab F, Borde J: Les indications opératoires dans les hydronéphroses de découverte anté-natale. Chir Pédiatr. 1989; 30: 249-52.

8. Novick AC, Streem SB: Surgery of the Kidney. In: Walsh P.C., Retik A.B., Vaughan E.D.Jr., Wein A.J. (ed.). Campbell's Urology. $7^{\text {th }}$ ed. Philadelphia, W.B. Saunders Co. 1998; pp 2973-3061, 1998.

9. Brookes JAS, Gordon I: Estimation of differential renal function in children with a prenatal diagnosis of unilateral dilatation. J Urol. 1997; 157: 1390-3.

10. Capolicchio G, Leonard MP, Wong C, Jednak R, Brzezinski A, Salle JL: Prenatal diagnosis of hydronephrosis: Impact on renal function and its recovery after pyeloplasty. J Urol. 1999; 162: 102932.

11. Steinhardt GF: Ureteropelvic Junction Obstruction. In: Gonzales ET, Bauer SB (ed.). Pediatric Urology Practice. $1^{\text {st }}$ ed. Philadelphia, Lippincott Williams \& Wilkins. 1999; pp 181-204.

12. Shortliffe LMD: Urinary Tract Infections in Infants and Children. In: Walsh PC, Retik AB, Vaughan ED Jr., Wein AJ (ed.). Campbell's Urology. $7^{\text {th }}$ ed. Philadelphia, W.B. Saunders Co. 1998; pp 1681-707.

13. Subramaniam R, Kouriefs C, Dickson AP: Antenatally detected pelvi-ureteric junction obstruction: concerns about conservative management. BJU Int. 1999; 84: 335-8.

14. Dhilon HK: Prenatally diagnosed hydronephrosis: the Great Ormond Street experience. Br J Urol. 1998; 81: 39-44.

15. Ross JH, Kay R, Knipper NC, Streem SB: The absence of crossing vessels in association with ureteropelvic junction obstruction detected by prenatal ultrasonography. 1998; 160: 973-5.
16. McAller IM, Kaplan GW: Renal function before and after pyeloplasty: Does it improve? J Urol. 1999; 162: 1041-4.

17. Salem YH, Majd M, Rushton HG, Belman AB: Outcome analysis of pediatric pyeloplasty as a function of patient age, presentation and differential renal function. J Urol. 1995; 154: 1889-93.

18. Hafez AT, Khoury AE: Renal functional impairment secondary to ureteropelvic junction obstruction: can pyeloplasty improve kidney function? Dial Ped Urol. 2000; 23: 5-6.

19. Koff SA: Postnatal management of antenatal hydronephrosis using an observational approach. Urology. 2000; 55: 609-11.

20. Koff SA, Campbell KD: The nonoperative management of unilateral neonatal hydronephrosis: Natural history of poorly functioning kidneys. J Urol. 1994; 152: 593-5.

21. Ulman I, Jayanthi VR, Koff SA: The long-term follow-up of newborns with severe unilateral hydronephrosis initially treated nonoperatively. J Urol. 2000; 164 : 1101-5.

22. MacNeily AE, Maizels M, Kaplan WE, Firlit CF, Conway JJ: Does early pyeloplasty really avert loss of renal function? A retrospective review. J Urol. 1993; 150: 769-73.

23. DiSandro MJ, Kogan BA: Neonatal management: role for early intervention. Urol Clin North Amer. 1998; 25: 187-97.

24. Ransley PG, Dhillon HK, Gordon I, Duffy PG, Dillon MJ, Barratt TM: The postnatal management of hydronephrosis diagnosed by prenatal ultrasound. J Urol. 1990; 144: 584-7.

25. Peters CA: Urinary tract obstruction in children. J Urol. 1995; 154: 1874-84.

26. Hanna MK: Antenatal hydronephrosis and ureteropelvic junction obstruction: the case for early intervention. Urology. 2000; 55: 612-5.

\author{
Correspondence address: \\ Dr. Luis Henrique Perocco Braga \\ Rua Minas Novas, 104 / 801 \\ Belo Horizonte, MG, 30310-090, Brazil \\ Fax: + 5531 3284-2775 \\ E-mail: perocco@terra.com.br
}

